\title{
SYNTHESIS OF RECONFIGURABLE SLOTTED WAVEGUIDE ARRAY ANTENNA
}

\author{
Abrahamyan H.V. \\ Radiophisical Reasrch Institute, Komitas ave. 49/4, Yerevan 0051, Armenia \\ Ph..: +37410234990, mob.: +37498109810, e-mail: ab_hrayr@yahoo.com
}

\section{Introduction}

Double mirror spherical antennas (DSA) are highly accurate and effective systems and are of great importance in antenna techniques. They are used in radio-astrology, remote space network and in other network spheres. The intensive development of the mentioned spheres entails the optimization of the antenna parameters. Accordingly the deliberate selection of the radiation system of those antennas is very important when solving a specific problem. For the optimatization of parameters of existing DSA and particularly the parameters of ROT-54/2.6 (radio optical telescope) [1] of Radio-physics Research Institute (RRI) Aragats Scientific Centre founded by RA academician Paris Herouni and for providing the multi-functionality the following conditions can be set on their radiation systems:

- During radio-astrological measurements it is essential to define the radiation field polarization of any cosmic object. For this it is necessary to provide the elliptic polarization of the radiation field.

- A multi-beam mode is required for increase in the effectivity of the distance scanning and for simultaneous observation of several objects

- The transformation of the RP is necessary when there are sources of interference in the observation area as well as for solving some target problems.

- A simultaneous maintenance of conducting and receiving operation mode.

Designing of the antennas with reconfigurable and electrical scanning radiation pattern that provide a multi-beam elliptic polarization, the optimization of the structure and parameters are of the most actual problems that require new solutions.

\section{Materials and methods}

There has been worked out a package (in Java and MatLab programming languages) for DSA modeling and quantitative evaluation of basic parameters as well as for defining the optimal view of the RP [2]. For providing different cases of amplitude distribution in DSA operating aperture the corresponding view of the radiator RP has been defined with the use of the program package. According to the implemented analysis, the ROT 54/2.6 secondary mirror optimal radiation condition, when we get the highest equal amplitude distribution in the antenna aperture, is provided if the index of radiator RP level under $119.7^{\circ}$ angle is lower by $20.4 \mathrm{~dB}$ from the RP highest index, and the width of RP main lobe is $9^{0}$. There have been defined the conditions for the change of the radiator RP view for providing the equability of amplitude distribution in the antenna's operating aperture caused by deformations conditioned by DSA movement in case of a radiator deviation from the focal location (table 1).

The data analysis makes it clear that within acceptable phase errors in case of the index increase of the radiator deviation from the focal location for maintaining the equability of amplitude distribution in the DSA aperture it is necessary to provide radiator RP main lobe width reduction as well as to provide the index reduction of the RP side lobe level in case of corresponding angle in the secondary mirror edges. It is to say that for the compensation of the equability break of the amplitude distribution in DSA aperture it is necessary to provide a dynamic reconfiguration of the radiator RP. 
Table 1.

\begin{tabular}{|c|c|c|c|}
\hline Focal distance & $\begin{array}{c}\text { The width of the radiator } \\
\text { RP main lobe } 2 \vartheta_{0,5} \\
(\mathrm{deg})\end{array}$ & $\begin{array}{c}\text { The radiation angle in } \\
\text { secondary mirror } \\
\text { edges (deg) }\end{array}$ & $\begin{array}{c}\text { The index of the radiator RP level } \\
\text { in case of the radiation angle in the } \\
\text { secondary mirror edges (dB) }\end{array}$ \\
\hline 0,5581 & 12 & 120,7 & $-19,4$ \\
\hline 0,5593 & 10 & 120,2 & -20 \\
\hline 0,56 & 9 & 119,7 & $-20,4$ \\
\hline 0,5604 & 8,4 & 119,5 & $-20,9$ \\
\hline 0,5607 & 7,2 & 119,3 & $-21,9$ \\
\hline 0,5611 & 6 & 119 & $-22,5$ \\
\hline 0,5615 & 5,7 & 118,8 & $-23,1$ \\
\hline 0,562 & 5 & 118,5 & $-24,4$ \\
\hline
\end{tabular}

There has been developed a sketch project for designing a reconfigurable, multi-beam slotted waveguide antenna array (SWA) radiator with an elliptic polarization of the field that meets the above given requirements. For providing the condition of the elliptic polarization of the SWA radiation field the method of vibratory antennas with elliptic polarization has been used. According to it the intervertical antennas with linear polarization in the surface will provide an elliptic polarization of the radiation field in case there is a 90 degree phase difference between their current phases [3]. We can provide a 90 degree difference between intervertical waveguides with linear polarization with the use of angular bypass method well-known in ultra high frequency (UHF) techniques [4]. We shall provide an elliptic polarization of the radiation field with a tri-step angular bypass (frame-like) of SWAs with linear polarization. For developing the antenna RP formula we use the RP multiplication method [5].

We observe the antenna array, which is composed of $N$ (the number) primary radiators that are extended on a certain $V$ distance. We use Deckard's coordinate system in a way that the SWA centre coincides with the origin of the coordinate system. We define the array radiation field in the observation point (point $R$ ). The complex amplitude of the electrical field vector of the radiation of the $n^{-}$th array element can be presented by through the following formula:

$$
\dot{E}_{n}=i C A_{n} \exp i \psi_{n} \frac{\exp \left(-i k r_{n}\right)}{r_{n}} F_{n}\left(\theta_{n}, \varphi_{n}\right) e_{n}^{0}
$$

here $A_{n}$ and $\psi_{n}$ respectively are the amplitude and phase of the field created by the $n$ - $^{\text {th }}$ aperture. $F_{n}\left(\theta_{n}, \varphi_{n}\right)$ is the RP of the $n{ }^{\text {th }}$ aperture. The aperture is a kind of magnetic vibrator. The RP can be calculated like the RP of an electrical vibrator:

$$
F_{3 / 4 \mathrm{~A}}(\theta)=\frac{\cos [(\pi / 2) \cdot \sin \theta]}{\cos \theta},
$$

$r_{n}, \theta_{n}$ and $\varphi_{n}$ are the spherical coordinates of point $R, e_{n}^{0}$ is the orth, which describes the polarization of the radiation field of the $n_{-}{ }^{\text {th }}$ aperture, $C$ is constant, which depends on the radiator type : $C=30 k \cdot l, k=\frac{2 \pi}{\lambda}$ is the wave number, $l$ is the length of the aperture.

The radiation field of the antenna array constitutes the vectoral sum of radiation fields of all the elements:

$$
\dot{E}=\frac{C A_{1}}{r} i e^{0} F_{n}(\theta, \varphi) \sum_{n=1}^{N} a_{n} e^{i \psi_{n}} e^{i k r_{n} \cos \alpha_{n}},
$$

If the elements of the array have different polarization, the radiation field of each element can be presented through the sum of $E_{\theta}$ meridian and $E_{\varphi}$ azimuthal constituents. 
$a_{n} e^{i \psi_{n}}=I_{n}$ is the current $n$-th aperture. Suppose $H_{10}$ basic wave is spread through the waveguide. In case of non-resonance system it is supposed that SWA apertures are stimulated with $\Delta \psi=2 \pi d / \lambda_{\mathrm{w}}$ ( $d$ is the distance between the apertures) phase deviations (for adjacent co-phase apertures) and $\Delta \psi=2 \pi d / \lambda_{\text {з́ }} \pm \pi$ (for adjacent interconnected apertures). I we take into consideration that in each case of SWA angular bypass the aperture stimulation phase changes by $\pi / 2$ then the power calculation algorithm should be developed in a way that after $n=\frac{N}{4}$ aperture (a single angular bypass) the aperture phase changes: $\psi_{n}=\frac{\pi}{2} m(m=1,2,3)$. $r_{n} \cos \alpha_{n}=x_{n} \sin \theta \cos \varphi+y_{n} \sin \theta \sin \varphi+z_{n} \cos \theta \cos \varphi$,

where $r_{n}$ is the $n$ aperture distance from the antenna central axis. It is limitary and is defined according to the evaluation of the DSA focal location parameters.

$\alpha_{n}$ is the angle formed between $r_{n}$ and the radius vector of the observation point,

$x_{n}, y_{n}$ and $z_{n}$ are the coordinates of the $n-^{\text {th }}$ aperture.

In formula (3) the sum presents the directedness multiplier of the system:

$$
f_{\Sigma}(\theta, \varphi)=\sum_{n=1}^{N} a_{n} e^{i \psi_{n}} e^{i k r_{n} \cos \alpha_{n}},
$$

The SWA radiation field dimension will be defined by the following formula:

$$
E=\frac{C A_{1}}{r} F_{n}(\theta, \varphi) f_{\Sigma}(\theta, \varphi)
$$

The SWA amplitude RP will be defined by the following formula:

$$
f(\theta, \varphi)=F_{n}(\theta, \varphi) \sum_{n=1}^{N} a_{n} e^{i \psi_{n}} e^{i k_{n} \cos \alpha_{n}}
$$

\section{Results and analysis}

There has been developed a model for calculating the frame SWA with the use of LabVIEW program package. At first calculation were done for static SWA in 6 sm length operation wave diapason to make sure that we provide mentioned requirements with this approach. According to calculation data there has been designed and made frame SWA in RRI base laboratory (fig. 1).

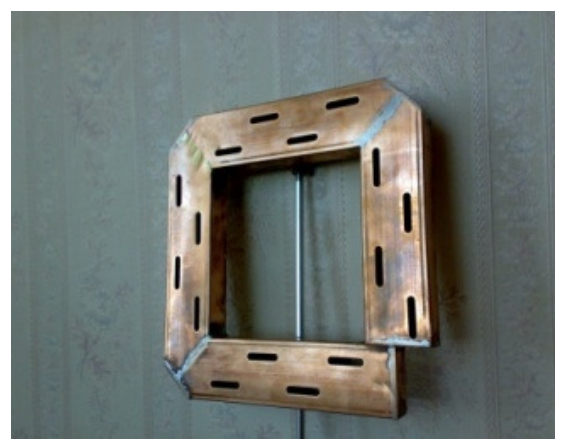

Fig. 1. Static SWA

According to the measurements the polarization ellipticality coefficient of the frame SWA is $k_{e}=0,81$, polarization ellipticality angle $-\beta=18^{0}$, gain $=11 \mathrm{~dB}$.

In combination with "National Instruments" tools there has been developed a laboratory stand for the measurement of the antenna RP and a measurement model with the use of LabVIEW program package has been designed [6]. 
The results of measurements and calculations of frame SWA RP respectively on horizontal and vertical surfaces are presented in fig. 2 .

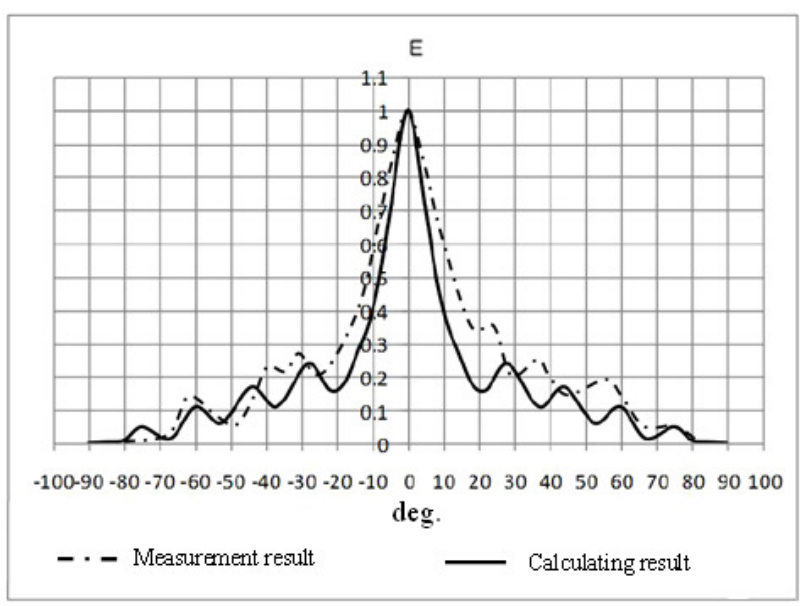

a) horizontal surface

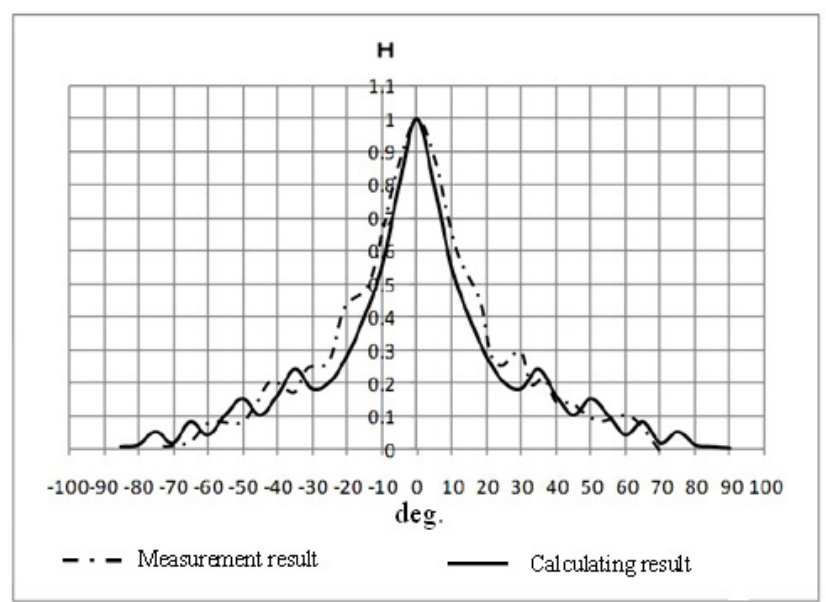

b) vertical surface

Fig. 2. Radiation pattern of frame SWA

Afterwards there has been sketched and made with elliptic polarization, reconfigurable, multibeam SWA radiator with 3cm-length operation wave for ROT 54/2.6 antenna in RRI base laboratory in 2009. The radiator consists of three frame SWA parts (fig. 3).

For the combined operation of the frame SWA parts there has been designed a supporting construction. Each part has its own power system. Such a selection of the power system enables to provide comutational, simultaneous conducting and receiving as well as multibeam operation mode.

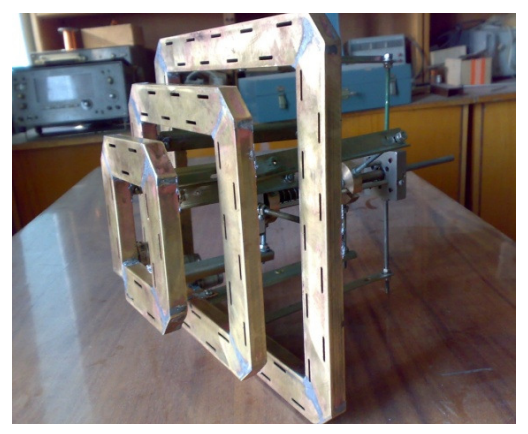

Fig. 3. Reconfigurable multi-beam SWA 


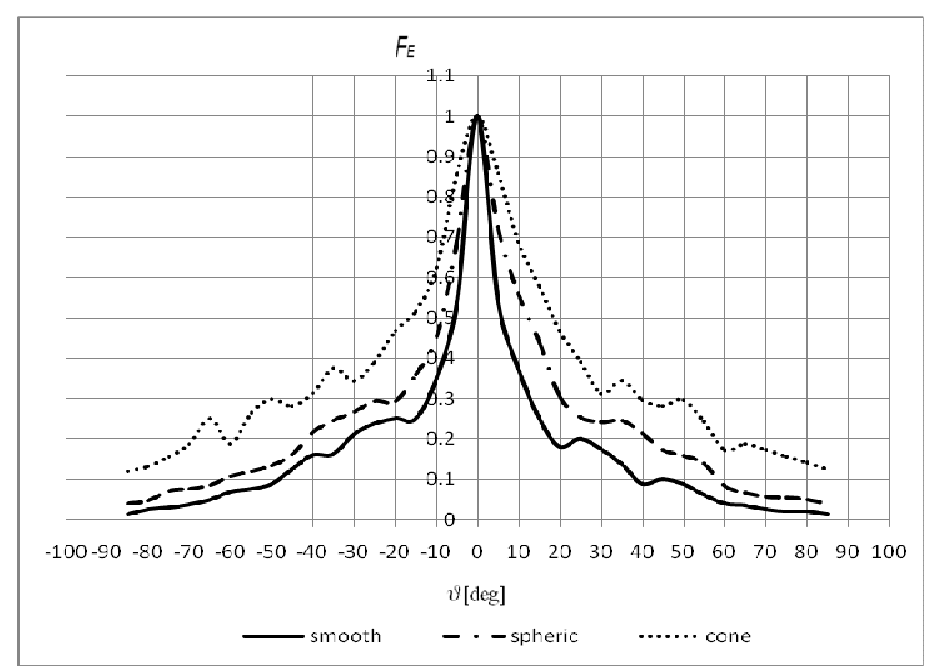

Fig. 4. Radiation pattern of Reconfigurable multi-beam SWA

Frame SWA parts can simultaneously work with similar as well as different frequencies this way providing the receiving of co-independent beams in the antenna aperture. The analysis of the measurement results makes it clear that the RP of each SWA part provides the required RP view of the radiator for DSA. The supporting construction provides for the simultaneous operation of the SWA parts along the central axis. Due to this peculiarity we provide the receiving of smooth, regimental and cone surfaces of the radiation. As a result of this we get different radiation parameters. The results of the measurements of the reconfigurable frame SWA RP in case of respectively smooth, spherical and cone surfaces are presented in fig. 4. The distance between the antenna parts is changed with $5 \mathrm{~mm}$-length steps and basic electrical parameters are measured. The results of the measurements are presented in table 2 .

Table 2.

\begin{tabular}{|c|c|c|c|c|c|c|c|c|c|c|c|}
\hline $\begin{array}{c}\text { SWA } \\
\text { reconfiguration } \\
\text { step (mm) }\end{array}$ & 0 & 5 & 10 & 15 & 20 & 25 & 30 & 35 & 40 & 45 & 50 \\
\hline $\begin{array}{c}\text { The width of } \\
\text { the } \\
\text { reconfigurable } \\
\begin{array}{c}\text { SWA RP main } \\
\text { lobe } \\
2 \vartheta_{0,5}^{\text {(deg) }}\end{array}\end{array}$ & 4,8 & 5,1 & 6,3 & 7 & 8,5 & 10 & 11,8 & 13 & 15,3 & 17 & 18,4 \\
\hline $\begin{array}{c}\text { The level index } \\
\text { of the } \\
\text { reconfigurable } \\
\text { SWA RP in } \\
\text { case of 119,7 } \\
\text { angle (dB) }\end{array}$ & -28 & $-24,2$ & -22 & $-21,7$ & $-21,1$ & $-20,8$ & -19 & $-18,7$ & -17.2 & $-16,4$ & -15 \\
\hline $\begin{array}{c}\text { Gain (dB) } \\
\text { Polarization } \\
\text { ellipticality } \\
\text { coefficient }\end{array}$ & 0.88 & 0.84 & 0.87 & 0.86 & 0.88 & 0.89 & 0.87 & 0.86 & 0.82 & 0.85 & 0.78 \\
\hline $\begin{array}{c}\text { Polarization } \\
\text { ellipticality } \\
\text { angle (deg) }\end{array}$ & 14 & 16 & 15 & 15.5 & 14 & 13.5 & 15 & 15.5 & 18 & 15,7 & 19 \\
\hline
\end{tabular}


In case of increase in the dimension of the distance between the SWA parts the width of the RP main lobe increases. Simultaneously the level of the SWA RP side lobe increases in case of $119,7^{0}$ angle (a radiation angle in the secondary mirror edges). According to the received data the maintenance of the radiation optimal condition of ROT 54/2.6 antenna radiator is received when the distance between SWA parts constitutes $25 \mathrm{~mm}$.

According to the data brought in the table 2 through the mechanical reconfiguration of this antenna we shall provide the changing conditions of radiator RP view for the maintenance of equal amplitude distribution in DSA aperture in case of radiator deviation from the focal location. The change in the reconfigurable SWA RP view can be achieved also through RP electrical oscillation typical to SWA's.

According to the measurements the overall mirror surface using factor is reduced by $6 \%$ in case of the highest possible radiator deviation from the DSA focal location (within acceptable indexes of phase deviation). It becomes possible to restore the surface using factor by $5.2 \%$ with reconfiguration of the SWA radiator.

\section{Conclusion and inference}

1. The calculation data received from the developed formula of the RP of multi-beam reconfigurable frame SWA with elliptic polarization of radiation field correspond to the results of experimental measurements.

2. The laboratory stand designed for the measurement of basic parameters of the antenna distant zone, in combination with National Instruments tools and the use of LabVIEW program package provides the efficiency and rapidity of the measurement.

3. With the use of the suggested multi-beam, reconfigurable frame SWA with an elliptic polarization of radiation field the deformation deviations conditioned by the motion can be minimized hereby providing equal amplitude distribution in DSA aperture. It is an optimal radiator for ROT- 54/2.6 antenna.

4. The antenna surface using factor can be corrected by $87 \%$ with the use of SWA-radiator in case of the radiator deviation from the focus location caused by different deviation deformations which in their turn are conditioned by ROT-54/2.6 antenna movement.

\section{References}

1. Heruni P. M. About Self Noises Radio-Optical Telescope ROT- 54/2.6 Antenna, Journal of Applied Electromagnestism, Trans-Black Sea Region Union of Applied Electromagnetismm pages. Athens, Greece.June 1999.-P. 51-57.

2. Minasyan V., Sargsyan A., Abrahamyan H. Design and calculation parameters of double reflector spherical antennas, Magazine Technical Sciences, National Academy of Sciences, Armenia /Yerevan/. - Part 63 №3, Yerevan 2010.-pp. 306-312.

3. Жук М. С., Молочков Ю.Б. Проектирование линзовых, сканирующих, шипокодиапазонных антенн и фидерных устройств. М.: «Энергия», 1973.- 440 с.

4. Справочник конструктора РЭА: Компоненты, механизмы, надежность /Н.А. Бараков, Б.Е. Бердичевский, П.Д. Верхопятницкий и др.; Под ред. Р.Г. Варламова.- М.: Радио и связь, 1985.-384 с.

5. Balanis C.A., Antenna Theory, Analysis and Design, 3rd ed., John Wiley \& Sons, New York, 2005. -P. 289.

6. Эйрамджян С.Г., Абраамян Г.В. Синтез и тестирование волноводно-щелевой антенной решетки с использованием оборудования National Instruments и LabVIEW // Образовательные, научные и инженерные приложения в среде LabVIEW и технологии National Instruments // Сборник трудов VIII Международной научно-практической конференции.- М.: РУДН, 2009.- С. 245-248. 